\title{
ASPECTOS SOCIOECONÔMICOS DA PESCA ARTESANAL DO CAMARÃO MARINHO NA ENSEADA DE LUCENA-PARAÍBA, BRASIL.
}

\author{
Glória Cristina Cornélio do Nascimento ${ }^{1}$ \\ Eduardo Beltrão de Lucena Córdula ${ }^{2}$ \\ Maria Cristina Basílio Crispim da Silva ${ }^{3}$
}

\section{Resumo}

A pesca artesanal com arrastão de praia é considerada uma das atividades mais antigas na costa brasileira. O presente estudo objetivou caracterizar o perfil socioeconômico dos pescadores dos arrastões de praia do município de Lucena-Paraíba, Brasil, assim como toda a atividade deste tipo de pesca. A aplicação de formulários semiestruturados ocorreu entre os meses de agosto e setembro de 2016 com (8) donos de arrastos e (43) ajudantes (puxadores de rede). A faixa etária entre os donos da rede variou entre 40-49 anos e os ajudantes 35-24 anos. A escolaridade apresentada na maioria foi o fundamental incompleto, porém ainda com incidência preocupante de analfabetos. A atividade de pesca ocorre todos os dias da semana com exceção dos domingos e os preços da produção do camarão sofrem alterações de acordo com a sazonalidade.

Palavras-chaves: Arrastão de praia, pescadores artesanais, caracterização socioeconômica.

\section{SOCIO- ECONOMIC ASPECT'S OF ARTISANAL FISHING OF MARINE SHRIMP IN LUCENA-PARAÍBA, BRAZIL.}

\begin{abstract}
Artisanal fishing with beach trawlers is considered one of the oldest activities on the Brazilian coast. The present study aimed to characterize the socio - economic profile of the fishertnen of the beach trawlers of the municipality of Lucena-Paraiba, Brazil, as well as all the fishing activity. The application of semi-structured forms was carried out between August and Septetnber 2016 with (8) owners of trawlers and (43) helpers (net handlers). The ages of the net owners varied between 40-49 and the helpers 35-24, Most of the fishermen had not finished their schooling and many were worryingly illiterate. Fishing activity happens every day of the week except for Sundays and shrimp production prices change according to the season.
\end{abstract}

Keywords: Beach trawler, artisanal fishermen, socioeconomic characterization.

\footnotetext{
${ }^{1}$ Doutora e Mestre pelo Programa de Pós-graduação em Desenvolvimento e Meio Ambiente - PRODEMA UFPB. Email: gccornelio@hotmail.com.

${ }^{2}$ Doutor e Mestre em Desenvolvimento e Meio Ambiente (PRODEMA-UFPB). Licenciado em Ciências Biológicas (UFPB). Email: ecordula@ hotmail.com.

${ }^{3}$ Doutora em Ecologia e Biossistemática pela Universidade de Lisboa (1997) e pós-doutorado na área de ecologia aplicada. Email: ccrispim@ hotmail.com.
} 


\section{SOZIO-ÖKONOMISCHE ASPEKTE DER HANDWERKLICHEN FISCHEREI VON MEERESGARNELEN IN DER BUCHT VON LUCENA-PARAÍBA, BRASILIEN.}

\section{Zusammenfassung}

Das handwerkliche Fischen mit Schleppnetzfischern am Strand gilt als eine der ältesten Aktivitäten an der brasilianischen Küste. Die vorliegende Studie zielt darauf ab, das sozioökonomische Profil der Fischer mit Hilfe der Schleppnetzfischerei am Strand der Gemeinde Lucena-Paraíba, Brasilien, sowie alle Aktivitäten dieser Art des Fischfangs zu charakterisieren. Die Anwendung von semi-strukturierten Formularen erfolgte zwischen August und September 2016 mit (8) Schleppnetzeigentümern und (43) Helfern (Schleppnetzzieher). Die Altersspanne der Schleppnetzeigentümer variierte zwischen 40 und 49 Jahren und die der Helfer zwischen 35 und 24 Jahren. Die Mehrheit hat nur einen unvollständigen Grundschulabschluss, aber dennoch mit besorgniserregender Häufigkeit von Analphabeten. Die Fangtätigkeit findet an allen Wochentagen mit Ausnahme der Sonntage statt, und die Preise für den Garnelenfangertrag ändern sich entsprechend mit der Saisonalität.

Schlüsselwörter: Strand-Schleppnetzfischerei, handwerkliche Fischer, sozio- ökonomische Charakterisierung

\section{INTRODUÇÃO}

As comunidades de pescadores existentes no litoral do Brasil entre os séculos XVII e o início do século XX viviam totalmente ou parcialmente da atividade pesqueira e estes com o passar do tempo criaram ou se adaptaram ao próprio meio para poderem explorar melhor o recurso natural do qual dependiam (SILVA, 1993). A pesca artesanal com arrastão de praia é considerada uma das atividades mais antigas na costa brasileira, sendo caracterizada como uma pesca não seletiva, apesar de ser direcionada para a captura de algumas espécies alvo (FAGUNDES et al., 2007). Além disso, a pesca com redes de arrasto praticada nas regiões tropicais e subtropicais é direcionada principalmente para a pesca do camarão, podendo ser encontrada pelo sistema tradicional em áreas costeiras ou de forma industrial em áreas marinhas com maior profundidade (plataforma continental) (BRAGA, 2000; ANDRIGUETTOFILHO,2002).

A pesca de arrastão de praia possui características técnicas e sociais inerentes a esta atividade, apresentando tecnicamente: prática artesanal de pequena escala e produção, sazonalidade de captura das espécies marinhas, força humana com utilização de apetrechos específicos e conhecimento tradicional relacionado com a atividade, e no aspecto social 
apresenta: coletividade, territorialidade, divisão peculiar na partilha dos lucros, percepção e grupos de trabalho definidos (PINHEIRO, 2007). Para Diegues (2004) essas práticas e modos de vida constroem-se em relação a um meio tanto físico quanto socialmente instável e imprevisível.

Os estudos envolvendo características socioeconômicas, descrição e manejo com arrastão de praia são escassos no Brasil, principalmente em relação à região Nordeste. Muitas destas pesquisas concentram-se entre o Sul e o Sudeste do País (ex: BAIL; BRANCO, 2007; FAGUNDES et al., 2007; SEDREZ et al., 2013; SILVA-GONÇALVES; D'INCAO, 2016). Faz-se necessário conhecer o perfil socioeconômico desses pescadores para que as condições de vida e o desenvolvimento de políticas públicas possam alcançar essas comunidades, visando não só a compreensão do modo de vida, escolaridade e baixos rendimentos, mas buscar soluções juntamente com estes, para o melhor desenvolvimento das atividades pesqueiras e também o desenvolvimento humano. A partir desta problemática o presente estudo objetivou caracterizar o perfil socioeconômico dos pescadores dos arrastões de praia do município de Lucena-Paraíba, Brasil, como também toda a atividade da pesca desenvolvida por eles, contribuindo assim para futuras propostas de gestão pesqueira ou políticas públicas na região.

\section{MATERIAIS E MÉTODOS}

\section{Área de estudo}

O município de Lucena localiza-se no litoral norte da Paraíba, sua área de extensão é de $88.944 \mathrm{~km}^{2}$ com aproximadamente $16 \mathrm{~km}$ de extensão de praia (FERNANDES et al., 2011). Possui uma população de mais de 11.545 habitantes (IBGE, 2010) com uma densidade de 122,6 hab./Km² (Figura 1):

Figura 1- Localização do Município de Lucena-Paraíba, Brasil.

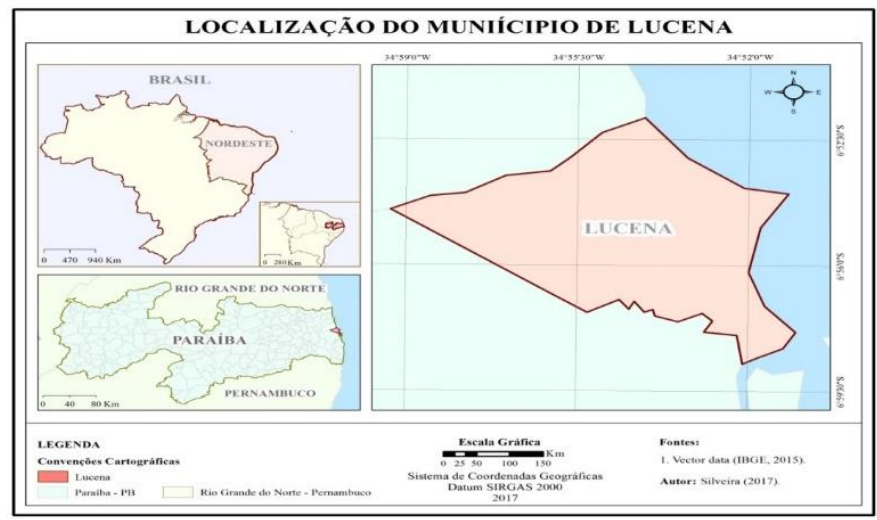


SOCIEDADE E

TERRITÓRIO
NASCIMENTO, Glória Cristina Cornélio do

CÓRDULA, Eduardo Beltrão de Lucena

SILVA, Maria Cristina Basílio Crispim da

\section{Coleta de dados}

Foi utilizado o método da observação não participante, consistindo na observação e registro livre dos fenômenos que são encontrados em campo (ALBUQUERQUE et al., 2010). Entrevistas livres foram realizadas (MINAYO, 2015) com alguns donos de rede de arrasto da cidade de Lucena para gerar informações mais detalhadas sobre a pesca e possibilitar a elaboração das questões a serem abordadas no formulário semiestruturado (ALBUQUERQUE et al., 2010), estes foram aplicados posteriormente no lugar e horário marcado com cada pescador no período de agosto a setembro de 2016. A técnica "Bola de neve" ("snowball") (BAILEY, 2008), foi utilizada ao final de cada formulário semiestruturado aplicado e teve como objetivo identificar os especialistas (donos de rede de arrasto) que serão procurados para posterior aplicação do mesmo formulário. Os puxadores de rede também foram entrevistados com a aplicação do formulário semiestruturado no momento em que realizavam as suas atividades na praia da cidade de Lucena. Esta pesquisa foi submetida ao Comitê de Ética da Universidade Federal da Paraíba e aprovada com o número de protocolo: 0211/15 CAAE: 445935154.8.0000.5188. Todos os participantes assinaram o TCLE (Termo de Consentimento Livre e Esclarecido) fazendo esta parte das Normas de Ética na Conduta da Pesquisa com Seres Humanos, da Resolução 466/12 do Conselho Nacional de Saúde (BRASIL, 2012).

\section{Análise de dados}

Os dados foram organizados e analisados por meio de tabelas através do software Microsoft Office Excel 2010 e apresentados no formato de tabelas e gráficos. Todas as respostas foram representadas por frequências absolutas e relativas. As respostas referentes às opiniões de alguns pescadores sobre a interferência dos viveiros de camarões também foram utilizados.

\section{RESULTADOS}

\section{Caracterização socioeconômica}

Atualmente na cidade de Lucena realizam a atividade de pesca de arrastão de praia 8 (16\%) pescadores dono de redes e 43 (84\%) ajudantes (puxadores de rede). A faixa etária entre os donos de redes de arrasto teve maior representação entre 40 e 49 anos (62,5\%) e entre os ajudantes entre 35-44 e 15-24 anos (30,23\% cada). O tempo médio de experiência na atividade 
da pesca de arrasto entre os donos das redes foi entre 30 e 39 anos (50\%). Os ajudantes por terem idades variadas apresentaram em sua maioria entre 1 mês a 10 anos de experiência (76,7\%). O grau de instrução dos donos de rede foi de 37,5\% para o ensino fundamental incompleto, analfabeto ou apenas escreve o nome $25 \%$ cada e $12,5 \%$ para o fundamental completo. Entre os ajudantes, o ensino fundamental incompleto apresentou maioria 48,84\% enquanto $27,91 \%$ afirmaram ser analfabetos. Ainda relataram ter o ensino médio incompleto $6,98 \%$, fundamental completo $2,33 \%$ ou que escrevem apenas o nome $13,95 \%$. Os ajudantes de pesca relataram que praticam essa atividade por falta de opção de trabalho $(48,8 \%)$ enquanto que os donos de rede afirmaram que os motivos para a prática dessa pesca são: a necessidade, o gostar e porque o pai foi pescador (25\% cada). A maioria dos donos de rede são casados, com renda média de um salário mínimo, naturais do município de Lucena (Tabela 1). A minoria possui freezer para armazenar o camarão e por consequência repassam para os "pombeiros" (atravessadores).

Tabela 1: Variáveis socioeconômicas dos pescadores (donos de rede) de camarão de Lucena-PB.

\begin{tabular}{|c|c|c|c|}
\hline Variável & Categoria & $\begin{array}{l}\text { Frequência } \\
\text { absoluta (n) }\end{array}$ & $\begin{array}{l}\text { Frequência } \\
\text { relativa }(\%)\end{array}$ \\
\hline Estado civil & $\begin{array}{ll} & \text { Casado } \\
\text { Solteiro } & \end{array}$ & $\begin{array}{l}6 \\
2\end{array}$ & $\begin{array}{l}75,0 \\
25,0\end{array}$ \\
\hline Renda média mensal & $\begin{array}{l}\text { 1 salário mínimo } \\
\text { - 1 salário minímo } \\
2 \text { salários mínimos } \\
\text { 2/5 salários mínimos }\end{array}$ & $\begin{array}{l}5 \\
1 \\
1 \\
1\end{array}$ & $\begin{array}{l}62,0 \\
12,5 \\
12,5 \\
12,5\end{array}$ \\
\hline $\begin{array}{l}\text { Realiza outra atividade } \\
\text { complementar }\end{array}$ & $\begin{array}{l}\text { Sim } \\
\text { Não }\end{array}$ & $\begin{array}{l}2 \\
6\end{array}$ & $\begin{array}{l}25,0 \\
75,0\end{array}$ \\
\hline Tem carteira de pescador & $\begin{array}{l}\text { Sim } \\
\text { Não }\end{array}$ & $\begin{array}{l}7 \\
1\end{array}$ & $\begin{array}{l}87,5 \\
12,5\end{array}$ \\
\hline Cidade de origem & $\begin{array}{l}\text { Rio Tinto-PB } \\
\text { Pernambuco- PE } \\
\text { Lucena-PB }\end{array}$ & $\begin{array}{l}1 \\
1 \\
6\end{array}$ & $\begin{array}{l}12,5 \\
12,5 \\
75,0\end{array}$ \\
\hline Possui freezer (quantidade) & $\begin{array}{l}0 \\
1 \\
2\end{array}$ & $\begin{array}{l}4 \\
1 \\
3\end{array}$ & $\begin{array}{l}00,1 \\
14,2 \\
85,7\end{array}$ \\
\hline
\end{tabular}


SOCIEDADE E

TERRITÓRIO
NASCIMENTO, Glória Cristina Cornélio do

CÓRDULA, Eduardo Beltrão de Lucena

SILVA, Maria Cristina Basílio Crispim da

Os donos de rede afirmaram que não realizam atividades de trabalho paralelo à pesca de arrasto $(75 \%)$, ao contrário dos ajudantes que em sua maioria praticam outras atividades $(69,7 \%)$. A maioria das atividades exercidas pelos ajudantes de rede fora da atividade de pesca é de servente de pedreiro, seguida de serviços gerais e agricultura. Além disso, os ajudantes responderam que não possuem carteira de pescador, nem registro na colônia de pescadores $(81,4 \%)$, enquanto os donos de rede apresentaram registro de pescador (87,5\%). Quando perguntados sobre o motivo da escolha da atividade os donos de rede em sua maioria responderam que foi por influência do pai, por necessidade e por que gosta de pescar $(25 \%$ cada) Quanto aos ajudantes a falta de opção predominou nas respostas $(48,84 \%)$ o que para os donos de rede ficou em (12,50\%). A frequência de respostas dos ajudantes para categoria “outros" (25,58\%) caracterizou-se em muitas justificativas como "a pesca é fácil”, "é um esporte", "é uma cultura", "não gosta de ficar parado" ou "precisa arrumar dinheiro para comprar roupa". Em nenhuma das respostas dos ajudantes surgiu o fato da necessidade do trabalho, ao contrário dos donos de rede (Figura 1).

Figura 1 - Motivos que levam os donos de rede da pesca do camarão e os ajudantes a praticarem a atividade da pesca de arrastão em Lucena-PB.

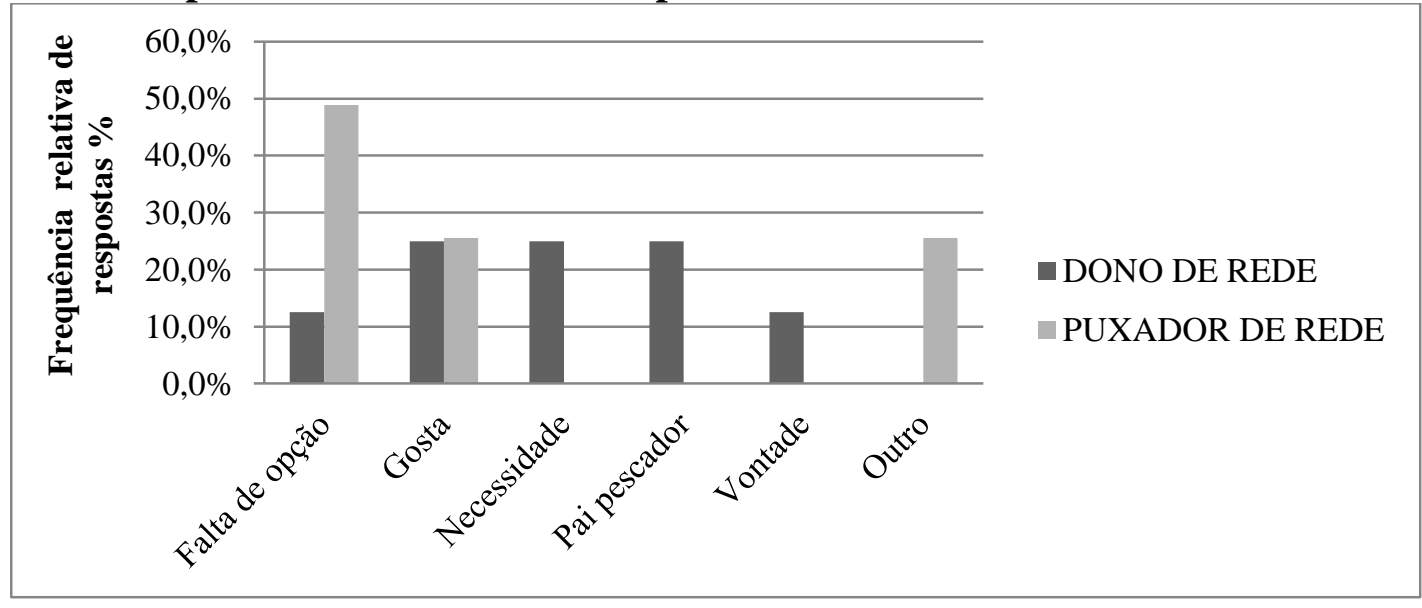

Fonte: dados da pesquisa.

Os pescadores donos de rede e os ajudantes foram também questionados sobre a possível implantação de defeso. A maioria dos ajudantes não sabia o que significava o termo "defeso" $(65,12 \%)$, provavelmente em consequência do pouco tempo na atividade e a falta de comprometimento, pois estão neste ofício sazonalmente, enquanto que 23,26\% disseram ser a favor da sua implantação. Os donos de rede em sua maioria, responderam $\operatorname{sim}(87,50 \%)$ para o 
defeso do camarão, demonstrando preocupação com o comprometimento da cadeia produtiva (Figura 2).

Figura 2 - Questionamento sobre a implantação de um possível defeso aos donos de rede de camarão e ajudantes na pesca de arrasto em Lucena-PB.

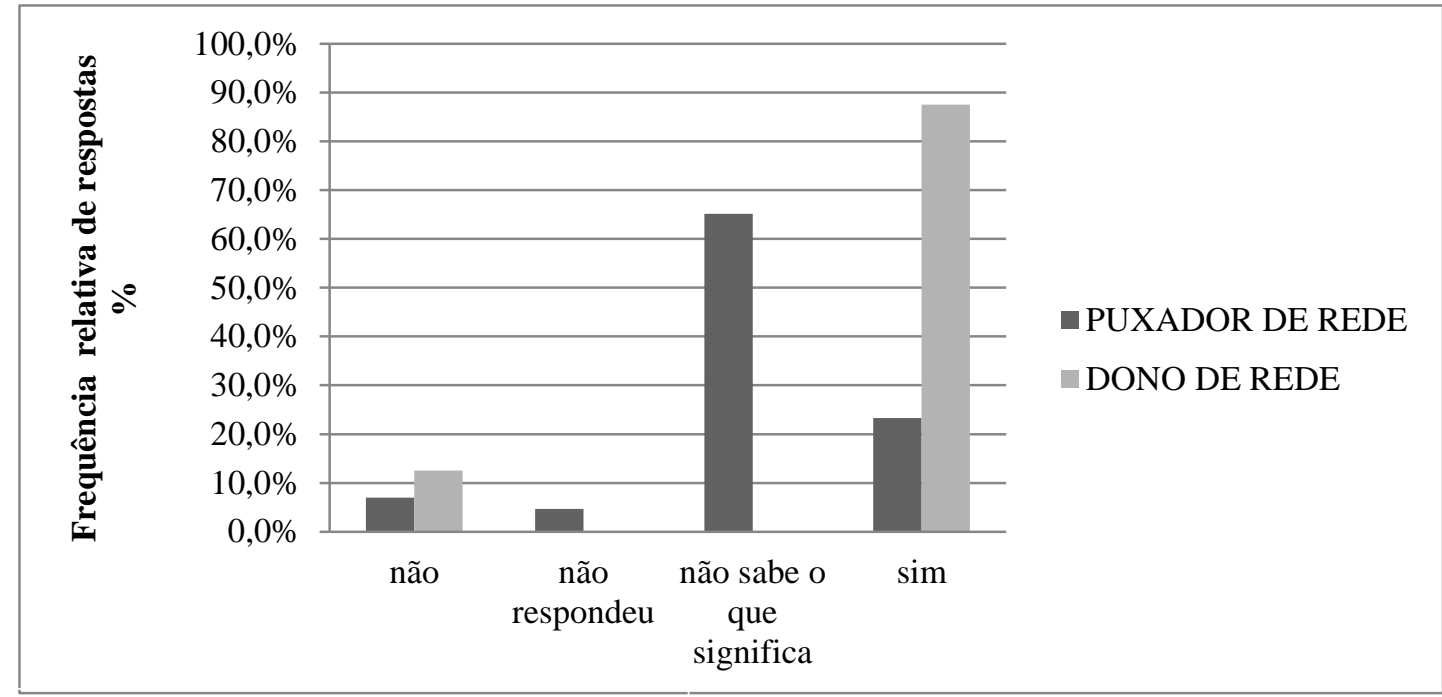

Fonte: dados da pesquisa.

Os ajudantes da pesca foram questionados quanto à possibilidade de possuírem uma rede de arrasto e ser independente. A maioria $(64,86 \%)$ afirmou que gostaria de ter uma rede de arrasto, justificando ser uma atividade que oferece oportunidade para as pessoas, traz poder econômico e dá prazer. Os 35,86\% que disseram não, argumentaram que essa atividade é "agressiva" e "dá muito trabalho e sofrimento". Estes ainda foram questionados se eram considerados pescadores ou apenas "puxadores de rede". A maioria se considera pescador $(39,53 \%)$, seguido apenas de puxador ou os dois $(30,23 \%)$ respectivamente. A relação de aprendizado revela que estes "puxadores de rede" em sua maioria, aprendem a atividade no dia a dia com os donos da rede $(46,51 \%)$, aprendem sozinhos e com o pai $(18,60 \%$ cada) ou com familiares ou amigos $(6,98 \%)$.

\section{Caracterização da pesca de arrasto:}

A pesca com a rede de arrastão de praia é utilizada em toda a faixa de praia da cidade de Lucena que possui aproximadamente $16 \mathrm{~km}$ de extensão. Todo o material da pesca fica disposto na faixa de areia em locais denominados de "estaleiros" (Figura 4a). A maioria dos pescadores donos da rede possuem barcos do tipo jangada (Figura 4b) para utilização na fase do "lance", que é a hora de soltar toda a extensão da rede em forma de "meia lua" dentro do 


\section{SOCIEDADE E \\ TERRITÓRIO}

NASCIMENTO, Glória Cristina Cornélio do

CÓRDULA, Eduardo Beltrão de Lucena

SILVA, Maria Cristina Basílio Crispim da

mar em locais determinados para a captura dos camarões a mais ou menos 300 metros da costa. O sistema de propulsão da jangada é uma vara de aproximadamente 3 metros (Figura 4b). Após cerca de $1 \mathrm{~h} 40 \mathrm{~m}$, tempo médio estimado para arrastar a rede, em que cada lado precisa de vários homens para puxa-la (Fig.4 c) dependendo das condições do clima, sedimento e presença de algas, o arrasto é finalizado, para dar início à “catação” dos camarões (Figura 3).

Figura 3: Fases da pesca de arrasto de camarão na praia de Lucena-PB: "estaleiro" e jangada (A), levando a rede para dar o "lance" (B), modo como a rede é arrastada para a costa $(C)$, retirada da rede de arrasto do mar (D).

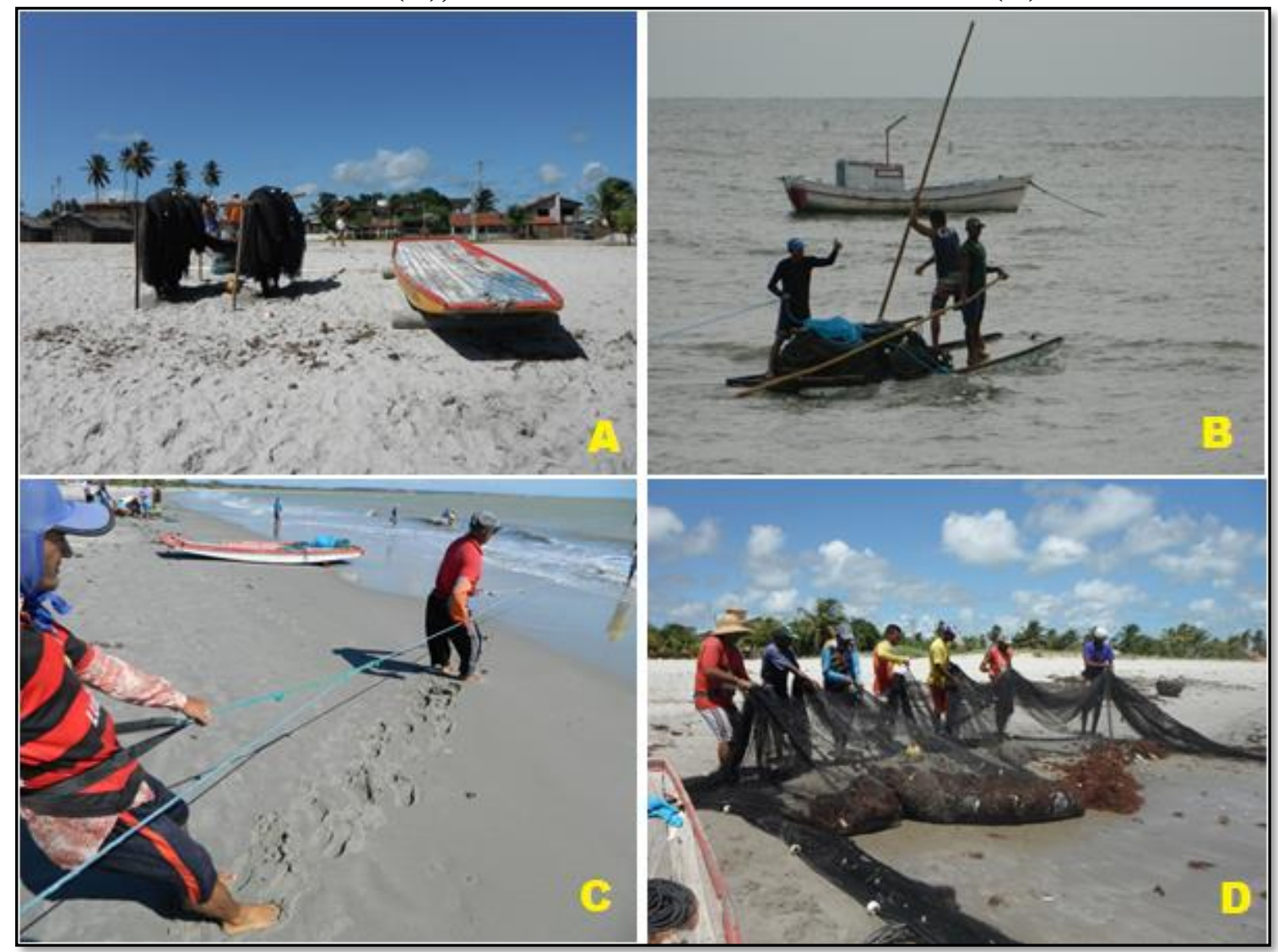

Fotos: Glória Nascimento (A) 2016; Eduardo Córdula (B, C, D), 2016

Atualmente a rede do arrasto é comprada pronta (pano de rede), os pescadores apenas colocam as boias na parte superior, o "capitão" (que é uma bóia guia, presa no meio da rede), o calão, as cordas, as boias e os chumbos. Segundo os pescadores donos da rede, o tamanho total da rede varia aproximadamente de 92 braças (138 metros) a 112 braças (168 metros). A medida em braças para esses pescadores equivale a 1,5 metros. O tamanho da malha depende de cada estrutura da rede que é dividida em: "calão", "manga", "encontro" e "copo" (Figura 4). 


\section{Figura 4: Desenho esquemático de uma rede de arrasto de camarão, dividida de acordo com o conhecimento dos donos da rede.}

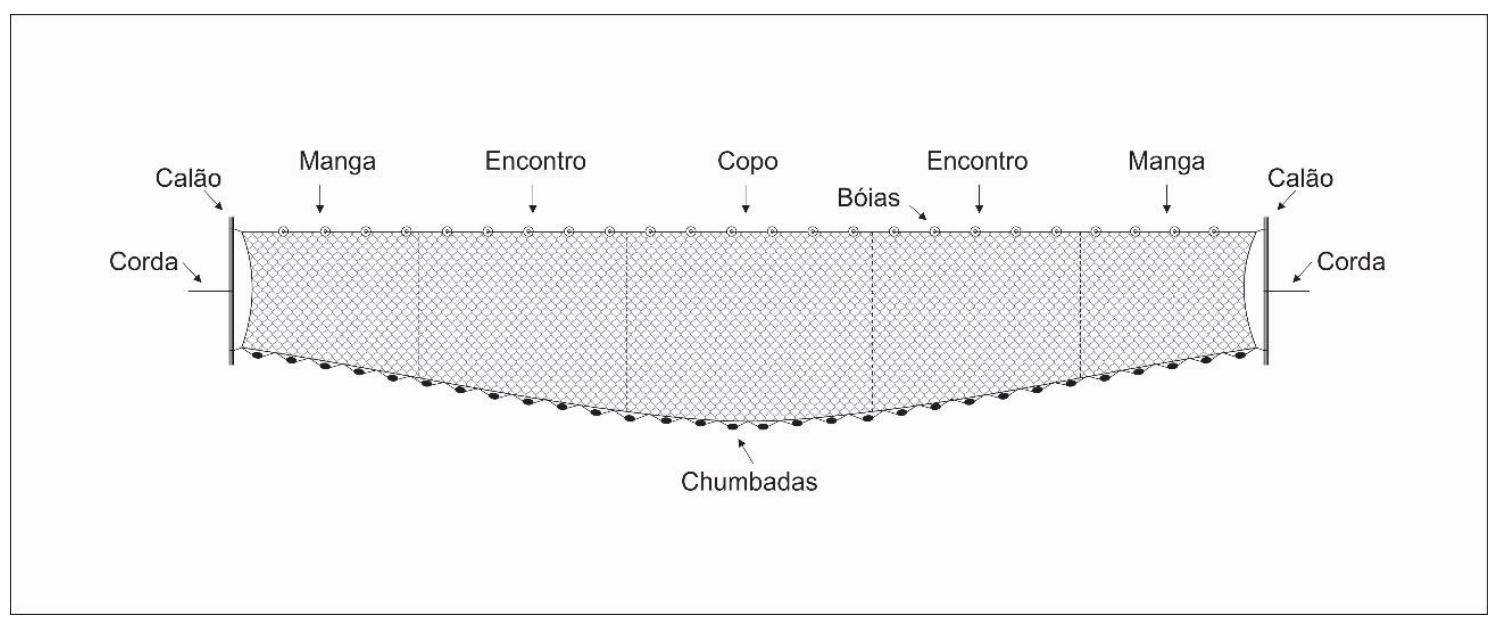

Ilustração: Designer Tainá Cornélio Fagundes

O “calão" $(2,5 \mathrm{~m})$ é uma vara de madeira amarrada às pontas de cada extremidade da rede de arrasto. Esta serve como apoio quando a rede se aproxima da costa e auxilia os pescadores a puxarem a rede para a praia. A "manga" é a extensão maior da rede variando seu tamanho entre 37 e 90 metros, dependendo do tamanho completo da rede. Esta possui malha 20. O "encontro" é a transição entre a manga e o copo, medindo entre 7,5 e 20 metros, com malha tamanho 15. Ao final da rede a estrutura responsável em juntar tudo que foi arrastado pela rede é o "copo". Este tem a forma de um "saco" e mede entre 12 e 30 metros possuindo malha 15 .

O "lance" seguinte é realizado logo em seguida, dependendo do que vier no arrasto anterior. Os puxadores de rede ajudam na catação do camarão, assim como algumas mulheres e outras pessoas que veem em busca de peixe. Os camarões são separados por espécie e tamanho, o Camarão "espigudo" (Xiphopenaeus kroyeri) é o menor e o camarão "branco" (Litopenaeus Schmitti) é o maior. A fauna acompanhante só é aproveitada pelo dono e os puxadores da rede se algum peixe for de tamanho comercial, os menores serão aproveitados por mulheres que auxiliam na catação.

Segundo os donos de rede o peixe só é vendido se vier em grande quantidade no arrasto, se não, é distribuído entre as pessoas que ajudam e os puxadores de rede, eles também 
SOCIEDADE E

TERRITÓRIO
NASCIMENTO, Glória Cristina Cornélio do

CÓRDULA, Eduardo Beltrão de Lucena

SILVA, Maria Cristina Basílio Crispim da

afirmaram que não aproveitam os peixes por não ter quem os limpe e também por que não têm a quem repassar.

O pagamento aos puxadores da rede é realizado no final de cada semana. A partilha da produção é chamada de "quinhão" que significa: a parte que lhe cabe. Na prática 30\% será destinada ao dono da rede e $70 \%$ dividido entre os puxadores.

A maioria dos donos de rede vende o camarão capturado no arrasto e o fazem passando para o "pombeiro" ou "atravessador". Quando questionados sobre porque passam a produção para os "pombeiros" a maioria relatou que não tem freezer em casa para armazenar o camarão, outros dizem que se acostumaram e que é muito trabalhoso armazenar em casa porque os vizinhos reclamam do mau cheiro.

Em seguida foram questionados sobre o que poderia melhorar a comercialização do camarão, 37\% disseram que uma associação seria a melhor solução, 25\% relataram que ter um local adequado para armazenamento seria ideal e 12,5\% apontaram que ter uma freguesia certa e uma época de defeso melhoraria as condições dos pescadores.

Os valores de venda do quilo do camarão assim como o total da produção semanal variam durante o ano (Tabela 2)

Tabela 2: Respostas dos pescadores quanto à produção do camarão em quilos e reais para venda numa semana "boa" e numa semana "ruim". Os valores foram resultado das médias de valores citado pelos pescadores no formulário semiestruturado.

\begin{tabular}{l|l|l|l|l}
\hline $\begin{array}{l}\text { ESPÉCIES } \\
\text { CAMARÕES }\end{array}$ & DE & $\begin{array}{l}\text { Camarão “espigudo” } \\
\text { (Xiphopenaeus kroyeri) }\end{array}$ & \multicolumn{2}{l}{$\begin{array}{l}\text { Camarão “branco" (Penaeus } \\
\text { schitti) }\end{array}$} \\
\hline $\mathrm{Kg} / \mathrm{R} \$$ & $\mathrm{Kg}$ & $\mathrm{R} \$$ & $\mathrm{Kg}$ & $\mathrm{R} \$$ \\
\hline Semana “boa" & 296 & $1-3$ & 40,8 & $30-50$ \\
\hline Semana "ruim" & 30,5 & $5-10$ & 7,0 & $20-25$ \\
\hline
\end{tabular}

Fonte: dados da pesquisa.

Os donos de rede ainda foram questionados sobre a criação de camarão em viveiros instalados no município. A maioria $(62,5 \%)$ respondeu que este tipo de produção afeta a pesca na praia por que segundo eles: 
"Primeiro a devastação do mangue e segundo, a despesca do viveiro, porque o produto que colocam no viveiro é largado dentro do estuário, cai dentro das camboas e mata a fiação”. E.C.N 68 anos

\author{
"Porque ele tira muitas toneladas e o preço é mais barato". J.D.F 42 anos \\ "Interfere, pois as pessoas compram barato de viveiro e não compram os da \\ praia”. S.F.D.F 49 anos
}

Outros pescadores $(37,5 \%)$, responderam que esse tipo de atividade não afeta a pesca deles porque os camarões dos viveiros são de uma espécie diferente dos que pescam na praia.

\title{
DISCUSSÃO
}

No Brasil, os estudos com os pescadores de camarão têm demonstrado características importantes entre as regiões do país. A pesca com arrastão de praia e o arrastão realizado pela frota industrial compartilham de algumas similaridades, porém este último destaca-se com a maioria dos trabalhos apontando as características socioeconômicas positivas destes pescadores.

Fagundes et al. (2007), estudaram uma comunidade que realiza a pesca com arrastão de praia na Ilha de São Vicente (SP) e observou que os pescadores/ajudantes tinham entre 26 e 40 anos, $48 \%$ destes apresentaram o ensino fundamental incompleto enquanto que $10 \%$ declarouse sem instrução. A maioria desses pescadores/ajudantes (60\%) exercem a pesca por necessidade de obter o alimento para a família e também praticam atividade paralela à pesca, em sua maioria na construção civil. De acordo com Ramires, Barrella e Estevens (2012), comunidades litorâneas localizadas ao sul do estado de São Paulo (30 municípios) também desenvolvem atividades paralelas à pesca artesanal como complemento da renda familiar, como atividades com o turismo, aluguel de barcos e serviços em casas de veranistas. Todas estas pesquisas corroboram com os resultados deste estudo.

Esses dados são relevantes, porque permite avaliar que esta atividade não é capaz de suprir as necessidades básicas de uma família, em virtude da baixa quantidade de pescado que é atualmente retirado do mar. O preço do camarão não é baixo no mercado, e o consumidor paga caro por receitas que incluam este ingrediente, assim é importante entender que os atravessadores acabam por ficar com parte do lucro deste produto, que poderia ficar com os pescadores, se estes tivessem melhores condições de armazenar o camarão e conseguissem manter mercados estáveis. Daí a importância de haver políticas públicas que auxiliem este 
SOCIEDADE E

TERRITÓRIO
NASCIMENTO, Glória Cristina Cornélio do

CÓRDULA, Eduardo Beltrão de Lucena

SILVA, Maria Cristina Basílio Crispim da

grupo de trabalhadores a organizarem e gerenciarem a atividade ao longo de toda a cadeia produtiva.

Na Paraíba, no município de Pitimbú, 23 pescadores atuam na pesca do arrastão de praia e possuem idade entre 19 e 68 anos, enquanto que apenas 8 destes possuem rede própria (MOURA, 2006). A presença de jovens com idade entre 13 e 17 anos é observada nos arrastões e afirmam que os parentes os pressionam para ajudar na atividade da pesca e que não pretendem seguir a profissão de pescador por perceberem ser um trabalho árduo e com pouca remuneração.

Estudos com pescadores do camarão sete-barbas (X. kroyeri) na Penha (SC) demonstraram que esses trabalhadores tinham faixa etária entre 40 e 50 anos e que possuíam experiência na pesca de 20 a 30 anos (45\%) (BAIL; BRANCO, 2007). Os pesquisadores ainda observaram que a maioria $(65,5 \%)$ dos pescadores apresentaram nível fundamental incompleto enquanto que 5,5\% relatou não possuir nenhuma instrução escolar. 92,7\% destes pescadores são associados à colônia de pescadores local. Os pescadores de arrasto de praia do estado de Alagoas, Brasil, pertencentes a área da APA dos Corais, possuem faixa etária entre 41 e 50 anos a maioria desses pescadores são analfabetos e não são os donos das redes (LIMA; SANTOS; CARVALHO, 2007). Relataram ainda que praticam apenas esse tipo de atividade para seu sustento e reclamam da exploração dos atravessadores, além disso, a maioria possui cadastro na colônia dos pescadores.

Comparando essas características com as dos pescadores de camarão da Praia de Lucena, verificam-se muitas similaridades, como por exemplo, a faixa etária geralmente mais elevada, e a baixa escolaridade. $\mathrm{O}$ fato de muitos se dedicarem à pesca não como atividade econômica única, realizando trabalho em paralelo na construção civil, revela que mantêm esta profissão por amor e não como fonte de renda principal. O amor pelo mar e pela pesca é um fator comum em comunidades pesqueiras, o que pode ser observado nesta pesquisa que mostra que cerca de $30 \%$ pescam porque gostam/vontade, no entanto, o baixo salário conseguido pela atividade obriga a que tenham outras atividades econômicas. Ainda há outro fator influenciador para a continuidade desta atividade, que são as relações intergeracionais, que segundo Moragas (1997) e Lopes (2005) "são relações que ocorrem entre indivíduos pertencentes a diferentes gerações que compartilham os mesmos eventos sociais, culturais e econômicos". O fato dos conhecimentos e práticas serem transmitidas de pais para filhos geram sentimentos ambivalentes entre os pescadores e sua família, segundo Garcia et al. (2007) os pescadores do 
município de Rio Grande - RS não desejam ver seus filhos na pesca por que esta envolve riscos e dificuldades econômicas, porém necessitam da sua ajuda e apoio acarretando o envolvimento desses na atividade. Ainda, segundo a pesquisa, os pescadores mais velhos veem a pesca como alternativa para os filhos caso estes não consigam prosseguir nos estudos.

A nomenclatura para determinar e caracterizar a rede de arrasto varia de acordo com cada localidade onde a pesca é realizada. Na costa do Rio Grande do Sul, Brasil, o arrastão de praia (artesanal) é conhecido como "picaré" ou "terno de costa", e se caracteriza com as seguintes partes: "côpo" ou "corpo", "encontro" que é uma parte da rede que se localiza entre o "copo" e o "subencontro" e "subencontro" localizado nos primeiros metros da rede, a rede pode apresentar tamanho entre 60 a 80 metros (MARQUES, 1980). Pinheiro (2007) no litoral do Paraná, Brasil, descreve redes de arrasto para a pesca da tainha em três partes: "mangas" ou “calões" que são as laterais da rede, “cópio" que é o local que os peixes ficam concentrados na captura e "cabos" que ficam amarrados em cada extremidade da rede. Na praia de Ponta Negra $(\mathrm{RN})$, Brasil, a rede de arrasto de praia possui 110 metros de comprimento com malhas entre 110 e 70mm. Geralmente o "lance" é realizado por dois pescadores com a embarcação do tipo catraia e a rede é puxada por seis a doze pescadores (GURGEL et al., 2014). Estudos de Moura (2006) em Pitimbú (PB), demonstraram que o arrastão de beira de praia ou mangotão possui três partes: "manga" com 15 ou $20 \mathrm{~mm}$ de malha, dois calões de 2,5 metros em cada extremidade da rede e o "copo" com malha de $15 \mathrm{~mm}$.

No estado de Santa Catarina em Porto Belo, Brasil, os pescadores do camarão sete barbas, relatam que após o período do defeso, em junho, a média da captura chega a 300kg por rede, anterior a esse período a captura mínima pode variar de 0,5 a $10 \mathrm{~kg}$ e no máximo de 150 a $120 \mathrm{~kg}$ (SEDREZ et al., 2013). Carvalho et al. (2000) apontaram que o Sudeste e Sul do Brasil são regiões onde há as maiores concentrações da pesca de camarões e que este pode ser um fator que explique baixos preços na região Nordeste, onde há baixa incidência da pesca com relação aos estados mencionados. Os autores ainda observaram que no município de Pontal do Peba (AL), Brasil, o camarão branco é pouco representativo na pesca, porém muito mais rentável que o camarão espigão que tem $64,44 \%$ de representatividade, estes fatores contribuem para os valores comercializados, sendo o camarão branco vendido a $\mathrm{R} \$: 8,93 / \mathrm{kg}$ equivalente a $5,91 \%$ do salário mínimo da época e o camarão espigão R $\$$ : 1,17/kg (0,8\%) (CARVALHO et al., 2000). No município de Pitimbú, litoral Sul da Paraíba o valor de venda do camarão branco na baixa estação varia entre $\mathrm{R} \$: 10,00 / \mathrm{kg}$ e $12,00 / \mathrm{kg}$, (2,85\%) e $(3,42 \%)$ respectivamente equivalente ao salário mínimo do ano 2006, enquanto que no período de veraneio (dezembro e 
SOCIEDADE E

TERRITÓRIO
NASCIMENTO, Glória Cristina Cornélio do

CÓRDULA, Eduardo Beltrão de Lucena

SILVA, Maria Cristina Basílio Crispim da

janeiro) os preços chegam a R \$: 25,00/kg (7,14\%) (MOURA, 2006). Em comparação com os dados encontrados nesta pesquisa, o camarão espigudo revelou menores valores na semana "boa" $(1,13 \%)$ e na semana "ruim" $(0,34 \%)$. Quanto ao camarão branco na semana "boa" $(5,68 \%)$ e semana "ruim" $(2,84 \%)$ o que demonstra que estes valores aumentaram com relação ao ano de 2006.

A comercialização final do camarão na maioria dos casos, é uma reflexão da situação econômica e social em que o pescador se encontra. As condições socioeconômicas do país (Brasil) geram problemas quanto à insegurança financeira, conduzindo-os a optar por empregos assalariados ou subempregos (BAIL; BRANCO, 2007). Segundo Oliveira (1988), a precariedade na infraestrutura e recursos financeiros levam esses pescadores a repassar a sua produção aos "atravessadores".

Em Lucena, Paraíba, observa-se que as dificuldades desses pescadores com infraestrutura, principalmente com armazenamento os leva a fazer esse tipo de comércio. Apenas um dos oitos donos de rede possui comércio próprio para a venda do camarão. Em Perequê (SP), os pescadores de camarão comercializam seu produto direto para o “atravessador" pois são destituídos dos meios para o seu processamento, diferentemente dos pescadores de São Paulo- Bagre (SP) em que toda a captura é destinada para o uso de iscas vivas, vendidas à unidade por $\mathrm{R} \$, 0,30$ centavos enquanto que em Perequê o preço é flutuante de acordo com o mercado (SOARES; SUZUKI; 2010).

No Maranhão o camarão Branco (L. schmitti) é comercializado diretamente ao consumidor local e atravessadores em estado natural enquanto que o camarão $X$. kroyeri passa por beneficiamento (torrado) e mesmo assim ainda é vendido por um baixo preço pois perde peso com esse processo (MONTELES et al., 2010). Viana, Camargo e Dutra (2015) propõem em seu estudo que para solucionar os problemas com a ineficiência de armazenamento do camarão no município de Caravela na Bahia, os pescadores deveriam criar associações ou cooperativas, a fim de possibilitar o maior controle do preço na compra e na venda.

A carcinicultura no Brasil alcançou rápido crescimento em pouco tempo devido às pressões econômicas e descaso dos órgãos fiscalizadores e como consequência causou insustentabilidade à atividade e sérios impactos socioambientais (QUEIROZ, 2007). Além disso, os conflitos causados pela atividade nas fazendas de criação de camarão também atingem 
questões como territorialidade com privatização de áreas de manguezais, prejudicando os pescadores que atuam nestes locais (PINTO et al., 2014).

A carcinicultura reflete na atualidade uma aparente "modernização" para o setor da pesca, porém muitos pescadores locais demonstram a sua percepção com relação aos impactos que esta atividade exerce sobre o ambiente (SILVA, 2012). Na comunidade de Livramento/ Santa Rita, Paraíba, 26,08\% dos pescadores afirmou que os viveiros de camarão utilizam produtos químicos para esterilizar os tanques e essa prática leva à mortalidade de muitos animais e plantas que habitam os manguezais, além disso, ainda apontam o assoreamento das camboas, que são pequenos canais de drenagem dentro dos manguezais, como consequência da descarga direta das águas dos viveiros de camarão, prejudicando assim o deslocamento destes pescadores no mangue (D’ANGELIS; MOURA, 2016).

Os impactos gerados pela carcinicultura tiveram interferência destrutiva na comunidade de Curral Velho/Acaraú, Ceará, pois segundo os pescadores essa atividade gerou alterações na qualidade e quantidade do pescado, poluição e desmatamento dos manguezais (NÓBREGA; MARTINS, 2010). A percepção dos pescadores artesanais sobre alterações no ambiente em que desenvolvem as suas atividades demonstra o conhecimento adquirido ao longo dos anos enquanto usufruem dos recursos naturais (SOUZA; VIEIRA; TEIXEIRA, 2010).

As propostas apresentadas pelos entrevistados demonstram a importância de serem realizados estudos sobre a pesca do camarão, com dados métricos, que permitam auxiliar na gestão desta pesca, inferir períodos de defeso e apresentar propostas de manejo adequado, visando à conservação desta atividade e deste recurso, tão importante para famílias de áreas costeiras.

Por outro lado, os pescadores apontaram a importância de uma Associação que tivesse infraestrutura para receber o camarão e poder fazer a venda, sem ser através dos atravessadores, isso melhoraria a sua renda e a permanência na pesca. Com infraestrutura adequada, seria possível até fazer o beneficiamento do pescado, aumentando ainda mais a renda auferida por essa atividade.

Vê-se com tudo isso, que a atividade de pesca de arrasto, apesar de ser algo milenar e vinculado à cultura local, é uma atividade que está em risco, principalmente pela dependência dos donos de rede com relação aos ajudantes/puxadores que não declaram ser esta atividade sua principal fonte de renda. Por outro lado, o recurso camarão é de grande interesse econômico e de grande valorização na culinária, dessa forma, ações de gestão que busquem manter a pesca artesanal do camarão são necessárias, de forma a tornar este tipo de pesca mais atrativo e com 
SOCIEDADE E

TERRITÓRIO
NASCIMENTO, Glória Cristina Cornélio do

CÓRDULA, Eduardo Beltrão de Lucena

SILVA, Maria Cristina Basílio Crispim da

garantia de manutenção, na competição com outras atividades por mão de obra, visto que a qualidade do camarão marinho é superior á do camarão de viveiro, pois este último tem sofrido influência química para a conservação com o metabissulfito (CRUZ, 2004).

\section{CONCLUSÃO}

A pesca de arrasto de praia é notoriamente uma atividade que resiste às mudanças ao logo do tempo, pois fatores externos como crescimento e expansão da cidade e consequentemente outras ofertas de trabalho surgem para mudar o cenário socioeconômico das pessoas que ali vivem. Outro aspecto importante são os jovens (puxadores de rede), que na maioria das vezes veem a atividade apenas como um "passa tempo" ou trabalho momentâneo. Os donos de rede têm dependência direta desses puxadores de rede e torna-se vulnerável essa relação por não haver continuidade ou repasse contínuo desse conhecimento. As famílias desses pescadores não têm participação ativa na atividade e seus descendentes não são estimulados a continuá-la podendo este fator levar a pesca do camarão à extinção.

Além disso, a sazonalidade e mudanças na quantidade da produção apontam alteração no manejo da atividade por esses pescadores. Essa situação aponta para a necessidade de orientação para uma possível implantação de associações, período de defeso ou beneficiamento do produto. Nota-se que a educação e informação levada para os pescadores revelam modos e expectativas de comercialização para um melhor aproveitamento de suas produções apesar da maioria possuir baixa escolaridade.

Deve-se ainda ressaltar a importância que o conhecimento desses pescadores revela com relação à cultura e tradições no aspecto de suas atividades com a arte de pesca. Trabalhos com pescadores de arrastão de praia são escassos e merecem maior atenção para que não fiquem no esquecimento da sociedade e para que possam ser incluídos em propostas de melhoria sociais, como moradia, saneamento, saúde e políticas públicas voltadas para a pesca de maneira a garantir a atividade, a conservação do recurso, incluindo período de defeso e propostas de atividades econômicas nesse período, como por exemplo o beneficiamento do camarão, de forma a garantir aumento de renda e consequentemente aumento na qualidade de vida para estas comunidades.

\section{REFERÊNCIAS}


ALBUQUERQUE, U. P. et al. Métodos e técnicas para coleta de dados etnobiológicos. In: Métodos e técnicas na pesquisa etnobiológica e etnoecológica, p. 41-64, 2010.

ANDRIGUETTO FILHO, J.M. Sistemas técnicos de pesca no litoral do Paraná: caracterização e tipificação. In: RAYNAUT, C. et al. (Ed.). Desenvolvimento e Meio Ambiente: em busca da interdisciplinaridade. Curitiba: Ed. UFPR. p. 195-211. 2002

BAIL, G. C.; BRANCO, J. O. Pesca artesanal do camarão sete-barbas: uma caracterização sócio-econômica na Penha, SC. Brazilian Journal of Aquatic Science and Technology, v. 11, n. 2, p. 25-32, 2007.

BAILEY, K. Methods of social research. $4^{\circ}$ ed, Simon and Schuster, 592p. 2008.

BRAGA, M. S. C. Pesca de arrasto de camarões na zona costeira do municipio de Fortaleza, Estado do Ceara. Fortaleza: CE, CTP, Engenharia de Pesca, 2000. Originalmente apresentada como dissertação de mestrado, Universidade Federal do Ceará, 2000.

BRASIL. Ministério da Saúde. Conselho Nacional de Saúde. Resolução n. 466, de 12 de dezembro de 2012. Aprova diretrizes e normas regulamentadoras de pesquisas envolvendo seres humanos. Brasília, Diário Oficial da União, 12 dez. 2012

CARVALHO, R.C.A. et al. Análise de custo e rentabilidade da captura e beneficiamento de camarão, Estados de Pernambuco e Alagoas, Nordeste do Brasil. Boletim TécnicoCientífico, CEPENE, Pernambuco, 8(1): 279-296. 2000.

CRUZ, R. R. M. O uso do metabissulfito de sódio na criação de camarão marinho em cativeiro e seu perigo para o trabalhador e o meio ambiente. Monografia de Especialização em Gestão Ambiental, Universidade de Fortaleza, 2004.

D'ANGELIS, I.; MOURA, G. O cenário social, econômico e ambiental da pesca artesanal em uma comunidade no litoral paraibano. REDE-Revista Eletrônica do PRODEMA, v. 10, n. $2,2017$.

DIEGUES, A. C. A pesca construindo sociedades. São Paulo: Nupaub-USP, 315p. 2004.

IBGE, 2010. Paraíba, Lucena. Disponível em:

http://cidades.ibge.gov.br/xtras/perfil.php?lang=\&codmun=250860. Acesso em: 03 set. 2016.

FAGUNDES, L. et al. A pesca de arrasto-de-praia na ilha de São Vicente, São Paulo, Brasil. Série Relatórios Técnicos, São Paulo, v. 29, p. 1-45, 2007.

FERNANDES, L. J. et al. Gestão costeira e desenvolvimento urbano do município de Lucena (PB-Brasil): Uma proposta de planejamento ambiental usando o Processo Analítico Hierárquico. Revista Gestão Costeira Integrada, 11(2): 219-232, 2011.

GARCIA, N. M.et al. Educando meninos e meninas: transmissão geracional da pesca artesanal no ambiente familiar. Psicol. educ. [online], n.25, pp. 93-112, 2007.

GURGEL, T.A.B. et al. Ocorrência e Caracterização de Peixes Marinhos da Praia de Ponta Negra, Rio Grande do Norte, Brasil. Biota Amazônia, v. 4, n. 3, p. 112-118, 2014. 
SOCIEDADE E

TERRITÓRIO
NASCIMENTO, Glória Cristina Cornélio do

CÓRDULA, Eduardo Beltrão de Lucena

SILVA, Maria Cristina Basílio Crispim da

LIMA, G. C.; SANTOS, M. C. F.; CARVALHO; R.C.A. Perfil social dos profissionais da penha de camarão marinho da APA costa dos corais, estado de Pernambuco e Alagoas (Brasil). Bol. Téc. Cient. CEPENE. Tamandaré, PE. V.15, n.1,97-108p. 2007.

LOPES, E.S.L. Relações Intergeracionais. In: Palavras-chave em Gerontologia, Ed. Alínea, Campinas, SP, 2005

MARQUES, L.A.B. O pescador artesanal do Sul. Rio de Janeiro, MEC - SEAC-FUNART, Instituto Nacional do Folclore, 75p. 1980.

MINAYO, M. C. S. Pesquisa social: teoria, método e criatividade. $34^{\circ}$ ed, Petrópolis, RJ: Vozes, 108p. 2015.

MONTELES, J. S. et al. Caracterização da Pesca Artesanal nos Municípios de Humberto de Campos e Primeira Cruz-Maranhão. Boletim do Laboratório de Hidrobiologia, v. 23, n. 1, 2010 .

MOURA, G. F. A pesca do camarão marinho (Decapoda, Penaeidae) e seus aspectos sócio-ecológicos no litoral de Pitimbú, Paraíba, Brasil. Recife: PE, CGT, Oceanografia, 2006. Originalmente apresentada como tese de doutorado, Universidade Federal de Pernambuco, 2006.

MORAGAS, R.M. Gerontologia Social Envelhecimento e Qualidade de Vida, Ed. Paulinas, SP, 1997

NÓBREGA, L. N.; MARTINS, M. P. M. J. Populações tradicionais, território e meio ambiente: um estudo sobre a carcinicultura e a comunidade de CURRAL VELHOACARAÚ/CEARÁ. Anais do XIX Encontro Nacional do CONPEDI realizado em Fortaleza, 2010.

OLIVEIRA, Z. O. P. Pesca artesanal: Problemas sociais e econômicos dos pescadores de Guaiúba.Imbituba (SC). Monografia apresentada no curso de Geografia. Fundação de Ensino Pólo Geoeducacional do Vale do Itajaí. 48 p. 1988.

PINHEIRO, L. O declínio da pesca de arrastão de praia face às mudanças nos regimes de uso e apropriação dos recursos pesqueiros no litoral do Paraná. Curitiba: PR, PG MEIO AMBIENTE E DESENVOLVIMENTO. Originalmente apresentada como tese de doutorado, Universidade Federal do Paraná. 2007.

PINTO, M. F. et al. Quando os conflitos socioambientais caracterizam um território? Gaia Scientia, v. 8, n. 2, 2014.

QUEIROZ, L. S. Na vida do Cumbe há tanto mangue: as influências dos impactos socioambientais da carcinicultura no modo de vida de uma comunidade costeira. 2007. Dissertação (Mestrado em Desenvolvimento e Meio Ambiente), Universidade Federal do Ceará/PRODEMA, Fortaleza, 2007. 
RAMIRES, M.; BARELLA, V.; ESTEVES, A. M. Caracterização da pesca artesanal e o conhecimento pesqueiro local no Vale do Ribeira e litoral sul de São Paulo. Revista Ceciliana, São Paulo-SP, jun, v. 4, n. 1, p. 37-43, 2012.

SEDREZ, M. C. et al. Caracterização socioeconômica da pesca artesanal do camarão setebarbas em Porto Belo, SC. Boletim do Instituto de Pesca, v. 39, n. 3, p. 311-322, 2013.

SILVA, L.G.S. Caiçaras e Jangadeiros: Cultura Marítima e Modernização no Brasil. CEMAR, USP. São Paulo. Brasil. 143 pp.1993

SILVA, E.C. Territorialidades e conflitos socioambientais no cotidiano da pesca artesanal na Comunidade do Porto de Jatobá, Abreu e Lima (PE). Revista Nordestina de Ecoturismo, Aquidabã, v.5, n.1, p.85-93,2012.

SILVA-GONÇALVES, R.; D’INCAO, F. Perfil socioeconômico e laboral dos pescadores artesanais de camarão-rosa no complexo estuarino de Tramandaí (RS), Brasil. Boletim do Instituto de Pesca, v. 42, n. 2, p. 387-401, 2016.

SOARES, F. C.; SUZUKI, J. C. Pesca e comercialização do camarão nas comunidades do Perequê e São Paulo- Bagre. In: Encontro Nacional dos Geógrafos: Crise, práxis e autonomia: espaços de resistência e de esperanças, espaço de diálogos e práticas,16., 2010, Porto Alegre, Anais... Rio Grande do Sul, 2010, p.1-15.

SOUZA, A. C. F. F.; VIEIRA, D. M.; TEIXEIRA, S. F. Trabalhadores da Maré: Conhecimento tradicional dos pescadores de moluscos na área urbana de Recife-PE. A Etnozoologia no Brasil: Importância, Status atual e Perspectivas. Volume, v. 7, n. 1, p. 151-176, 2010.

VIANA, D. F.; CAMARGO, E.; DUTRA, G. F. Avaliação econômica da pesca do camarão sete-barbas, Xiphopenaeus kroyeri (Heller, 1862), no município de Caravelas-BA, Brasil. Boletim do Instituto de Pesca, v. 41, n. 2, p. 419-428, 2015.

Recebido em Agosto de 2018

Aceito em Agosto de 2019

Publicado em Dezembro de 2019 